\title{
FACTORS AFFECTING CUSTOMERS' BEHAVIOR TOWARDS TIPPING INTENTIONS IN JORDANIAN RESTAURANTS
}

\author{
Hakam SHATNAWI ${ }^{*}$ \\ Yarmouk University, Faculty of Tourism and Hotel Management, Hotel Management \\ Department P.O Box 566 ZipCode 21163, Irbid - Jordan, e-mail: Hakamss@yu.edu.jo \\ Bashar Al NAJDAWI \\ Al-Balqa Applied University, Faculty of Aqaba College, Hotel Management \\ and Tourism Science Department, Aqaba - Jordan, 19117, e-mail: najdawi@bau.edu.jo
}

\section{Khaldoun KANAAN}

Al-Balqa Applied University, Faculty of Aqaba College, Hotel Management and Tourism Science Department, Aqaba - Jordan, 19117, e-mail: kknanaan@bau.edu.jo

\section{QUSAY KHALEEFAH}

Al-Balqa Applied University, Faculty of Aqaba College, Hotel Management and Tourism Science Department, Aqaba - Jordan, 19117, e-mail: Q.khaleefa@bau.edu.jo

\section{Mohammad KHASAWNEH}

AL-Balqa Applied University, Faculty of Ajloun Collge, Department of Financial and Administrative Sciences, Ajloun - Jordan, 26816, e-mail: khasawnehmohammad79@bau.edu.jo

Citation: Shatnawi, H., AL-Najdawi, B., Kanaan, K., Khaleefah, Q., \& Khasawneh, M. (2019). FACTORS AFFECTING CUSTOMERS' BEHAVIOR TOWARDS TIPPING INTENTIONS IN JORDANIAN RESTAURANTS. GeoJournal of Tourism and Geosites, 26(3), 761-768. https://doi.org/10.30892/gtg.26307-395

\begin{abstract}
Jordan is considered as a peaceful and stable destination in the Middle East region. Restaurants are considered the backbone of the hospitality business in Jordan. They contribute to (40 \%) of tourism employment in 2018. This article aims to discuss the factors affecting tipping intentions. A convenient sample of 624 clients was selected from restaurants in Irbid governorate, which is considered as the second-largest populated city in Jordan. The questionnaires were distributed and collected from the respondents in all 35 fine-dining restaurants working in Irbid, in order to explore the factors affecting the customers' behaviors towards tipping intentions. According to the results of this study, about $20 \%$ of the variation in the tipping intentions is attributed to service quality, food quality, restaurant environment, emotional motivations, and social motivations. Food quality has a larger effect in explaining the variation in tipping intentions as compared to the rest of the investigated factors. There was no difference between males and females towards their tipping intentions. Older frequent clients have more tipping intentions than other groups in the study community. The study recommended conducting similar surveys on other restaurant types in different governorates in Jordan as well as in neighboring countries to understand the tipping behavior of restaurant clients in different contexts.
\end{abstract}

\footnotetext{
* Corresponding author
} 
Hakam SHATNAWI, Bashar Al NAJDAWI,

Khaldoun KANAAN, Qusay KHALEEFAH, Mohammad KHASAWNEH

Key words: Tipping, Gratuity, Restaurants, Customers' Behavior, Jordan

$* \quad * \quad * \quad * \quad *$

\section{INTRODUTION}

The restaurants sector is considered as a major sector in the hospitality business, at least based on its economic contribution and employability. One of the most important service sectors that their workers depend on this type of common behaviors known by both the service providers (waiters, hosts, servers) and clients. The nature of the services in the restaurant industry makes it difficult for the administration to monitor the performance of the waiters and the quality of services provided to clients in restaurants. Therefore, customers' feedback is regarded as a vital part of the service monitoring and enhancement process. Tipping is considered as a major indicator of customer satisfaction and repeated visits (Lynn \& Sturman, 2010). Gratuity, tip, or baksheesh are synonyms of one term describing one human behavior during some of their daily interactions with service providers. Clients usually pay some extra money on their bills to service providers in hotels and restaurants as an appreciation for the service provided (Jessica, 2015; Saayman, 2014; Azar, 2007b). It is known that human beings always seek to maximize utility by giving money only when they will get something in return, and they try to pay as little as possible as rational economic customers (Abraham, 2014).

Tips are usually given after the provision of services. Staff members cannot change the service quality in response to the amount of tip offered by customers (Jessica, 2015). Therefore, this behavior is considered bizarre. The culture of tipping is widely spread in many countries. It has become a global phenomenon and a form of socio- cultural behavior at the same time (Abraham, 2014), while some cultures such as the Japanese culture refuses this behavior (Casey, 2001). The great economic impact of the tips on a large number of workers in different sectors, including the restaurant sector, and the dependence of many workers with low salaries on tips makes it interesting to explore this research field. Understanding this culture gives us an indication of the extent to which clients are satisfied with the provided services. This may be used by restaurant managers and owners as an indicator on the service quality and client's satisfaction. On the other hand, restaurant staff could use various strategies and actions to increase their income through tipping. The economic impact of tips is substantial. Millions of workers around the world depend on tips as an additional source of income (Saunders \& Lynn, 2010). Tips in the food industry in the US alone count for 47 billion dollars annually (Azar, 2010a).

Since the tipping is a deliberate and voluntary action, its explanation lies only in human motivation (Lynn, 2015). The most commonly asked questions when it comes to tips are: why human beings pay amounts of money they are not obliged to pay, especially after already receiving the service? Why some clients pay tips and others do no't? And why some pay relatively big payments while others pay little? No doubt that it is difficult to know what makes a person pay and makes others abstain from paying and whether the client's personality and characteristics are the reasons behind such a decision, or there are other reasons associated with the service and environment of the restaurant. Although the phenomenon has been well studied worldwide, Jordan lacks for any research on this topic. This study attempts to explain the main motives behind the tipping behavior and the relationship between tipping on one hand, and factors such as service and food quality, restaurant environment, emotional motives, and social motives on the other hand in Jordanian restaurants. Therefore, this study attempts to answer the following questions: what are the main motives influencing client's intention to pay tips? Is there a 
statistically significant relationship between clients' motives and buying intention? And does tipping behavior vary according to the demographic variable of the study sample?

\section{TIPPING CONCEPT}

Researchers argued about the origin of the word "Tip", some say it's a Latin word derived from the word "stips" which means "gift", and some say that it was derived from the Dutch word "Tippen" which means "Tap" "as "tapping the table with a coin to get the attention of the service provider", while others think that it was derived from the gypsy statement "Tipper me your money" (Lynn et al., 1993). Lynn et al., (1993) define tipping as an additional amount of money that is provided by clients to employees in order to compensate for services rendered, a form of social behavior that is influenced by values and customs. Casey (2001) proposes that money exchanged between a customer and a service provider is not subject to a particular law. Lynn (2015) points out that tipping is a deliberate voluntary act of clients directed at employees as gifts in exchange for the services provided to them. It can be said that many of the researchers that have studied this subject have indicated and agreed on a set of points: The voluntary and deliberate nature of tipping behavior, tipping as a small amounts of money paid after receiving the service; usually (10-15\%) of bill amount, there is no law governing the size or form of this behavior, and the complexity of this economic and social phenomenon.

\section{ORIGINS OF TIPPING BEHAVIOR}

There is no confirmation by researchers in this domain on the origins of tipping, but they suggest that this behavior originated in the Middle Ages when feudalists threw coins to groups of beggars to buy safe passage for them on the road. Adding to that, those feudalists used to pay some extra money to their servants as a kind of appreciation for them (Azar, 2004). In Tudor England, private home visitors were tipping the servants who served them during their visit to these houses, known as "vails". The Americans, who visited Europe at that time, transferred the habit to US to prove their wealth and to prove their knowledge of the traditions of other countries. By the end of the $18^{\text {th }}$ century, tipping had become an established fact in American society (Abraham, 2014). According to Azar (2004) and Brenner (2001), the origins of the tipping date back to the sixteenth century when some copper jars were placed in cafes and bars with this statement "To Ensure Promptitude" written on them, to ensure speed of service. So, it is believed that the origin of the word "tip" goes back to the initials of the previous sentence "To Ensure Promptitude" (Tip). In the Arab region, the Turks shaped part of the culture of the region, and the word "Baksheesh", according to some writers, came from the Turkish culture and it means what is provided to those who perform a simple service. Tipping culture has become widespread in most Arab countries and many workers in the food industry and other sectors rely heavily on tipping to support their low wages (Abdel Moneim, 2007; Marzouki, 2018; Badran et al., 2013).

\section{REASONS AND MOTIVATIONS OF TIPPING}

Lynn (2017) and Lynn \& Brewster (2018) argued that people like the policy of tipping voluntarily and do not prefer it to be in a form of fees included in the bill. Many researchers agree that tipping behavior is an avoidable expenditure form. Many ask why consumers leave money to strangers when they are not legally obliged to do so, and do not gain any tangible benefit out of it (Lynn et al., 1993). Others pointed out that one of the main reasons for tipping workers is that it has become a social norm, and the provision of tips conform to social norms and customs, and this commitment of tipping gives them social acceptance and make them feel generous (Azar, 2007a). On the other hand, 
disobeying this norm causes them embarrassment in front of others (Bodvarsson \& Gibson, 1999; Aronson et al., 1999). This is consistent with the theory of Social Exchange. Azar (2003) asserts that some provide tips as a kind of sympathy for low-income workers or as a means of expressing their own kindness and generosity, while some feel strong and superior when practicing this behavior. The other reason according to Conlin et al. (2003) is the desire to have better future services. This applies to clients who want to return to the same restaurant and expect to be served by the same people.

The idea is that, through tipping, employees are motivated to provide better services in return, and sometimes customers fear that not paying tips may lead to bad services at the next visit. Thus, some people would take the initiative to pay tips. This is what (Hiler, 2015) calls the "Influence motive" which is based on the fact that the consumer wants to control current and future services. The customers give the tip because they realize that the quality of service provided by the waiter is not included in the bill and feel that the only way, they can reward employees is by tipping (Lynn, 2001). Liraz (2012) discusses that the relationship between service quality and tipping intention depends on the food quality. Wang (2010) points out that that tipping began as a sign of gratitude and appreciation and then as an expression of social status and an incentive, and finally became a custom and a socially accepted fact. In addition, Saayman (2014) conducted an exploratory survey in restaurants during the Ardklop Festival in South Africa to find out the drives that make people pay tips or abstain from paying.

The results of the study showed that the reasons for tipping are due to financial reasons, the result of good service and to gain social acceptance. Also, it showed that the behavioral variables are more influential than social and demographic variables in influencing the decision to pay the tip. Lynn (2015) revealed a motivational frame that offers reasonable interpretations for the motives of paying or not paying the tips. The so-called TMF (Tipping Motives Framework) presumed that tipping is motivated by the desire of customers to welfare the servers and build fair relations with staff, getting privileged services in the future visits and finally conforming to the social commitment or gain social acceptance. Lee and Dewald (2016) conducted a study on the tipping behavior of Chinese tourists in American restaurants. Although the culture of tipping is not widespread in China, the Chinese tourists were paying tips in different rates under the influence of the prevailing social custom in the USA, depending on the level of service provided. The main influencing factors of their tipping intentions were food prices, companions in the visit, and food. Moreover, Azar (2010b) proposed that people do not consider strategic motives represented in future service, but they consider social and psychological motives while tipping.

\section{METHODOLOGY}

The researchers used the descriptive-analytical approach. A survey was conducted among a purposive sample visiting all 35 fine-dining restaurants working in Irbid city; northern Jordan during May 2018-Jan 2019. In designing the questionnaire, the researchers reviewed some of the previous studies regarding tipping Behavior (Mok \& Hansen, 1999; Artuger \& Çetinsöz, 2013; Jessica, 2015; Al Najdawi et al., 2017; Shatnawi, 2019). A questionnaire consisting of five dimensions influencing the tipping behavior of clients (Service Quality, Restaurant Environment, Emotional motives, Social motives, and Food Quality), was distributed among a purposive sample of 690 clients dining in these restaurants and 624 questionnaires were returned and analyzed to comprehend clients' opinion on the main dimensions of tipping and determine the statistical correlations between the main variables of the study. 


\section{DATA ANALAYSIS AND RESULTS}

The demographic distribution of the study sample reveals that $73.7 \%$ were male clients, $36.1 \%$ were between $41-50$ years old, $32.4 \%$ were less than 3oyears old, and the rest were evenly distributed between those between 31-40 and more than 50 years old. The majority $(34,1 \%)$ visited restaurants once every two weeks, followed by those who visited restaurants once a week (26\%) and least were clients who visited restaurants on a daily basis (9\%). Table 1 shows the Means and standard deviations of responses related to the motives which affect the intention of the customers to pay tips. Service quality and food quality were the main variables influencing the intention of clients to pay tips, whereas emotional motives were the least. Agrees with (Liraz, 2012), who confirmed a strong correlation between quality of service and the tip value. The detailed analysis of the variables influencing client intention to pay tips revealed that staff training, service style, cleanliness, price, quantity, taste, and price of food, importance of personal hygiene and the cleanliness of the restaurant are the most important variables that affect the client's intention to pay tips for workers in the restaurant. A standard multiple regression test was conducted to identify the impact of the group of variables (service quality, the restaurant environment, food quality, emotional motives, and social motives) and the dependent variable (Tipping Intention), the results as shown in Table 2.

Table 1. Overall mean and Standard Deviations of the study main dimensions

\begin{tabular}{|c|c|c|c|}
\hline Dimension & N & Mean & Std. Deviation \\
\hline Service Quality & 624 & 4.1294 & .64226 \\
\hline Restaurant Environment & 624 & 3.3437 & .74269 \\
\hline Emotional motives & 624 & 2.6597 & 1.04583 \\
\hline Social motives & 624 & 2.8085 & .93315 \\
\hline Food Quality & 624 & 4.1218 & .52155 \\
\hline
\end{tabular}

Table 2. Standard Multiple Regression tests

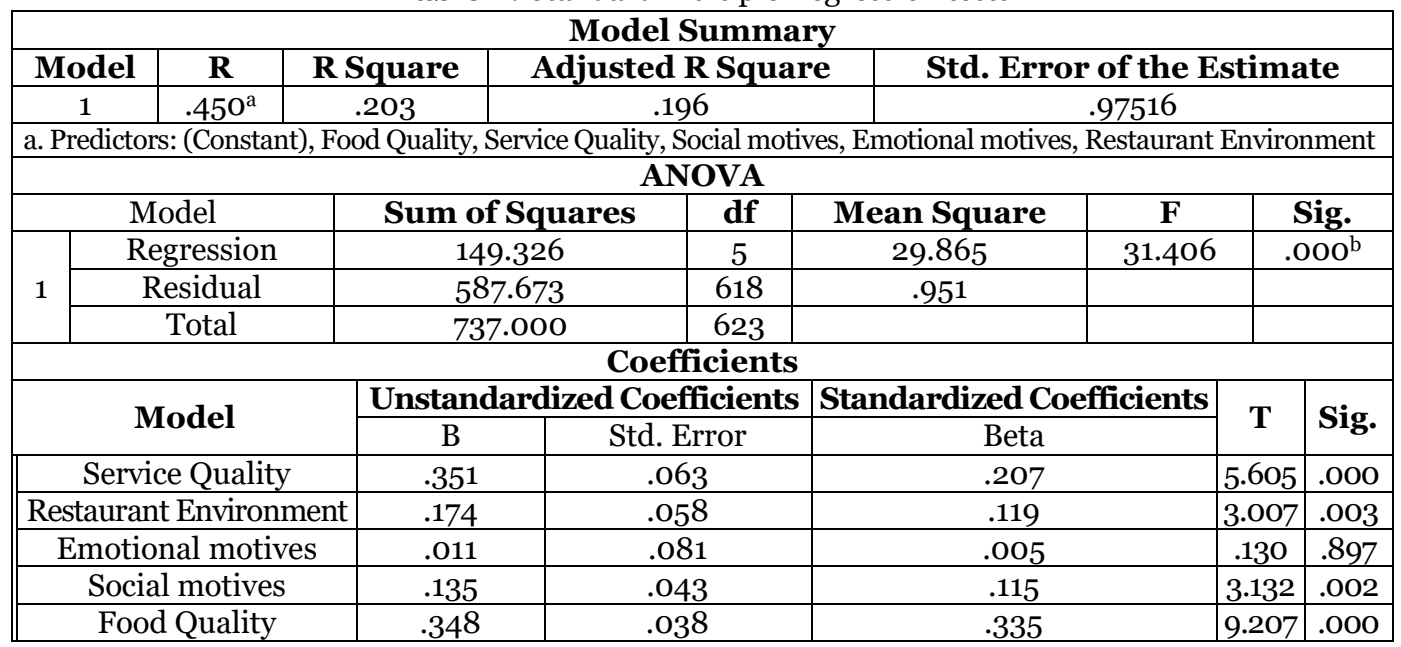

According to the findings in Table 2 the value of the correlation coefficient between the dependent variable (Tipping Intentions) and the independent variables (service quality, the restaurant environment, food quality, emotional motives, and social motives) counted for $0.450(\mathrm{R}=.450)$ and the independent variables explain about $20 \%(\mathrm{R}$ Square $=.203$ ) of the variance in the intention to pay Tips. It is clear that the regression is 
significant (Sig. $=0.00$ ) and the value of the variance $\mathrm{F}=31.406$. This simple interpretative value of the influence of the group of the independent variables that had been studied certifies to us that there are many variables that might have a larger influence on the intention to pay tips, but they were not studied in this research. In order to explain the value of each independent variable (service quality, the restaurant environment, food quality, emotional motives and social motives) in the intention to pay the tips, it is clear to us that the variable of emotional motives was not statistically significant ( $\mathrm{Sig}=.897)$ which is greater than the standard level of significance (0.05) ,and therefore did not have an effect in the regression equation, while the other independent variables were statistically significant and thus have an effect on the interpretation of variation in the tipping intention, where the value of the coefficient (Beta $=.335$ ) of the food quality variable and the calculated value of (T) (9.207), followed by the Service Quality Variable (Beta $=.207 / \mathrm{T}=5.605$ ). This result is completely different from what Azar, 2010a had said, who emphasized that people pay tips for social and psychological reasons only, not for strategic reasons and for future service considerations. It is in line with Speer, 1997; Rønhovde, 2012; Artuger \& Çetinsöz, 2013; Cho, 2014, who confirmed that quality of service is the most important factor in leaving tips. Further analysis was conducted to comprehend the significant differences between the responses of the members of the study sample towards the variable of tipping intention according to the different demographic factors. It is clear that the value of the statistical significance of the $\mathrm{T}$ test for two independent samples were (0.110) which is greater than the level of significance $(\mathrm{a}<=0.05)$. Thus, we conclude that there are no statistically significant differences between the means of study sample estimates towards the tipping intention attributed to sex factor. This finding agreed with Jewell, 2008. To find out the statistical relationship between the study sample responses towards the tipping intention according to the number of visits to restaurants, one-way ANOVA analysis was conducted as shown in Table 3.

Table 3. One -Way ANOVA Test for a number of visits to restaurants variable

\begin{tabular}{|c|c|c|c|c|c|c|c|c|}
\hline \multirow{2}{*}{ Descriptive } & \multirow{2}{*}{$\mathbf{N}$} & \multirow{2}{*}{ Mean } & \multirow{2}{*}{$\begin{array}{c}\text { Std. } \\
\text { Deviation }\end{array}$} & \multicolumn{5}{|c|}{ ANOVA } \\
\hline & & & & & Sum of Squares & dff & $\mathbf{F}$ & Sig \\
\hline Rarely & 100 & 3.0000 & 1.08886 & $\begin{array}{l}\text { Between } \\
\text { Groups }\end{array}$ & 29.426 & 4 & \multirow{3}{*}{6.436} & \multirow{3}{*}{.000} \\
\hline Once a month & 93 & 3.6371 & .94158 & $\begin{array}{l}\text { Within } \\
\text { Groups }\end{array}$ & 707.574 & 619 & & \\
\hline $\begin{array}{c}\text { Once every two } \\
\text { weeks }\end{array}$ & 213 & 3.6045 & 1.00556 & Total & 737.000 & 623 & & \\
\hline Once a week & 162 & 3.5417 & 1.15333 & & & & & \\
\hline Daily & 56 & 3.4241 & 1.20691 & & & & & \\
\hline Total & 624 & 3.4800 & 1.08765 & & & & & \\
\hline
\end{tabular}

The results shown in Table 3 show that the level of the sign (sig) corresponding to the value of the $\mathrm{F}$ test is $(0.000)$ and is less than the significance of $(\mathrm{a}=0.05)$. As a result, there are statistically significant differences in the estimates of the study sample towards the intention to pay tips attributed to the variable of a number of restaurant visits. To find out the significance of the differences between the samples, the Tukey test was conducted. And it showed what is clarified in Table 4, that there were significant differences between rarely category and once per month category in favor of once per month category which had the highest mean value 3.6371. There were also differences between rarely and once every two weeks categories in favor of the group once every two weeks with the highest mean value of 3.6045. There were also differences between rarely and once per week 
category in favor of once a week category which had the highest mean (3.5417). This means that the sample member who visits restaurants weekly or monthly has a tendency to pay tips more than the survey sample members who rarely visit restaurants.

This interpretation may be associated with the idea of seeking future services as they will repeat the visit in the future, which is consistent with Conlin et al., (2003). For age group, One-Way ANOVA test was conducted. The results show that the level of a significance corresponds to the value of $\mathrm{F}$ test (0.002), which is less than the significance level of $\mathrm{p}<0.05$. Accordingly, there are statistically significant differences in the study sample estimates towards the tipping attributed to the age variable. To detect the significance of the differences between the samples, Tukey test was conducted for differences between the samples, and it revealed significant differences between the age group (less than 30 years) and (41-50) category in favor of the age group (41-50) ) which had the highest mean of (3.6544) and the statistical significance of (0.002). This means that the older age groups are the ones who have the highest intention to pay the tips in the Jordanian restaurants. This is consistent with Lynn (2006) and disagrees with (Jewell, 2008) study, which indicated that young people have more tendency to pay tips.

Table 4. Post Hoc Test for a number of visits to restaurants variable

\begin{tabular}{|c|c|c|c|c|}
\hline \multicolumn{5}{|c|}{ Multiple Comparisons } \\
\hline $\begin{array}{c}\text { (I) Visit restaurants } \\
\text { every month }\end{array}$ & $\begin{array}{c}\text { (J) Visit restaurants } \\
\text { every month }\end{array}$ & $\begin{array}{c}\text { Mean } \\
\text { Difference (I-J) }\end{array}$ & Std. Error & Sig. \\
\hline Once a month & Rarely & $.63710^{*}$ & .15402 & .000 \\
\hline Once every two weeks & Rarely & $.60446^{*}$ & .12961 & .000 \\
\hline Once a week & Rarely & $.54167^{*}$ & .13597 & .001 \\
\hline
\end{tabular}

\section{CONCLUSION}

This exploratory study can be considered as a real addition to the literature related to the behavior of tipping in Jordan and the Middle East. One of the main findings of the study is that the variable food quality and service quality are the most important reasons creating tipping intention, so it must be taken into consideration by employees and managers in restaurants. The study also found that older age groups and the groups who have more frequent visits to restaurants had greater intentions to pay tips. Unlike other dimensions of the study, social motive did not have an effect on the interpretation of the tipping intention. There was no difference in the tipping intention according to clients' gender, while it is found that old people have more intention to tip than young clients. Clients who visits restaurants on weekly or monthly basis have a tendency to pay tips more than those who rarely visited restaurants. The study recommended conducting similar surveys on other restaurant types in different governorates in Jordan as well as in neighboring countries to understand the tipping behavior of restaurant clients in different contexts.

\section{REFERENCES}

Abdel Moneim, A. (2007) Tipping a culture whose principles differ from one society to another. Issue 10441, Middle East Newspaper. 30 June 2007.

Abraham, Z. (2014). The Influence of National Culture on Tipping Behavior.

Al Najdawi, B.M., Khaleefah, Q., Shatnawi, H., \& Al Momani, E. (2017). Measuring local tourists' perceptions in Petra city as one of seven wonders of world. Journal of Environmental Management \& Tourism, 8(18), 427-435.

Al-Marzouqi, M. (2018) Tipping. 2018, No. 1001, Al-Bayan Newspaper, 10/3/2018.

Aronson, E., Wilson, T.D. \& Akert, R.M. (1999). Social Psychology, Addison-Wesley Longman, New York, NY.

Artuger, S., \& Çetinsöz, B.C. (2013). Factors influencing the tipping propensity of restaurant customers: A study in 5 -star hotels a la carte restaurants. International Journal of Business and Social Science, 4(17), 70-78. 


\section{Hakam SHATNAWI, Bashar Al NAJDAWI, Khaldoun KANAAN, Qusay KHALEEFAH, Mohammad KHASAWNEH}

Azar, O.H. (2003). The implications of tipping for economics and management. International Journal of Social Economics, 30(10), 1084-1094.

Azar, O.H. (2004). The history of tipping-from sixteenth-century England to the United States in the 1910s. The Journal of Socio - Economics, 33(6), 745-764.

Azar, O. H. (2007a). The Social Norm of Tipping: A Review 1. Journal of Applied Social Psychology, 37(2), $380-402$.

Azar, O.H. (2007b). Why pay extra? Tipping and the importance of social norms and feelings in economic theory. The Journal of Socio-Economics, 36(2), 250-265.

Azar, O.H. (2010a). Do people tip because of psychological or strategic motivations? An empirical analysis of restaurant tipping. Applied Economics, 42(23), 3039-3044.

Azar, O.H. (2010b). Tipping motivations and behavior in the US and Israel. Journal of Applied Social Psychology, 40(2), 421-457.

Badran, N.A., Gad, H.E., \& Ma'uof, M.A. (2013) Server attitudes and restaurant tipping: tip enhancing actions, faculty of tourism and hotels journal, Suez Canal University, Egypt.

Brenner, M.L. (2001). Tipping for Success: Secrets for How to Get in and Get Great Service. Brenmark, Sherman Oaks, CA.

Casey, B. (2001). Tipping in New Zealand restaurants. Cornell Hotel and Restaurant Administration Quarterly, 42(1), 21-25.

Cho, S.B. (2014). Factors Affecting Restaurant Consumers' Tipping Behavior. Journal of the Korean Society for Quality Management, 42(1), 15-32.

Conlin, M., Lynn, M., \& O’Donoghue, T. (2003). The norm of restaurant tipping. Journal of Economic Behavior \& Organization, 52(3), 297-321.

Hiler, J.L. (2015). The role of motives and decision rules in restaurant tipping, LSU Doctoral Dissertations. 2036.

Jessica, J. (2015). Factor influencing customers tipping behavior in restaurant in LUZERN. Journal Hospitality dan Manajemen Jasa, 3(2), 13-27.

Jewell, C.N. (2008). Factors Influencing Tipping Behavior in a Restaurant. Psi Chi Journal of Undergraduate Research, 13(1).

Lee.P, Dewald.C, (2016) Tipping Practices of Chinese Tourists in U.S. Restaurants: An Exploratory Study. Journal of Tourism and Hospitality Management, Vol. 4, No. 2, pp. 17-34. DOI: 10.15640/jthm. v4n2a2.

Lynn, M. (2001). Restaurant tipping and service quality: A tenuous relationship. Cornell Hotel and Restaurant Administration Quarterly, 42(1), 14-20.

Lynn, M. (2006). Geodemographic differences in knowledge about the restaurant tipping norm. Journal of Applied Social Psychology, 36(3), 740-750.

Lynn, M. (2015). Service gratuities and tipping: A motivational framework. Journal of Economic Psychology, 46, 74-88.

Lynn, M. (2017). Should US restaurants abandon tipping? A review of the issues and evidence.

Lynn, M., \& Brewster, Z. W. (2018). A within-restaurant analysis of changes in customer satisfaction following the introduction of service inclusive pricing or automatic service charges. International Journal of Hospitality Management, 70, 9-15.

Lynn, M., \& Graves, J. (1996). Tipping: an incentive/reward for service? Hospitality Research Journal, 20 (1), 1-14.

Lynn, M., \& Sturman, M C. (2010). Tipping and service quality: A within-subjects analysis. Journal of Hospitality and Tourism Research, 34(2), 269-275. Reprinted with permission. All rights reserved.

Lynn, M., Zinkhan, G. M., \& Harris, J. (1993). Consumer tipping: A cross-country study. Journal of Consumer Research, 20(3), 478-488.

Medler-Liraz, H. (2012). Service quality and tipping: The moderating role of the quality of food. International Journal of Hospitality Management, 31(4), 1327-1329.

Mok, C., \& Hansen, S. (1999). A study of factors affecting tip size in restaurants. Journal of Restaurant \& Foodservice Marketing, 3(3-4), 49-64.

Rønhovde, A.S. (2012). Relationship between service quality and tipping in Norway: Do perceived service quality and other factors have a relationship with tip size in Norwegian restaurants? (Master's thesis, University of Stavanger, Norway).

Saayman, M . (2014) To tip or not to tip? African Journal of Hospitality, Tourism and Leisure Vol. 3 (2).

Saunders, S.G., \& Lynn, M. (2010). Why tip? An empirical test of motivations for tipping car guards. Journal of Economic Psychology, 31(1), 106-113.

Shatnawi, H.S. (2019). Effect of a waitresses's head scarf (Hijab) on tipping behavior in restaurants. African

Journal of Hospitality, Tourism and Leisure, 8 (4).

Speer, Tibbett. (1997). "The Give and Take of Tipping." American Demographics (February): 51-54.

Wang, L. (2010). An Investigation and analysis of US restaurant tipping practices and the relationship to service quality with recommendations for field application.

***MOTA, (2019). Ministry of Tourism \& Antiquities, https://www.mota.gov.jo/Contents/Statistics.aspx.

Submitted:

26.06.2019
Revised:

09.09.2019
Accepted and published online

11.09.2019 